\title{
ANALISA KUALITATIF DAN KUANTITATIF KANDUNGAN ALKOHOL PADA TAPAI KETAN DI KOTA BATUSANGKAR
}

\author{
Maya Sari $^{1 *}$, Najmiatul Fajar ${ }^{2}$ \\ ${ }^{I}$ Tadris Kimia, Fakultas Tarbiyah dan Ilmu Keguruan, IAIN Batusangkar \\ ${ }^{2}$ Tadris Biologi, Fakultas Tarbiyah dan Ilmu Keguruan, IAIN Batusangkar \\ Jalan Sudirman No. 137 Lima Kaum Batusangkar, Kab. Tanah Datar \\ *Email: mayasari@iainbatusangkar.ac.id
}

\begin{abstract}
The black sticky tapai/ Tapai ketan hitam in Batusangkar, made by fermentating black sticky rice and yeast. The fermentation of black sticky tapai take several days to produce a sweet taste. This process may some assumption that the sweetness in black sticky tapai comes from alcohol as a result of sticky rice fermentation reaction with yeast. As the time of fermentation increases alcohol content, this raises doubt the halalness of black sticky tapai, because based on MUI Fatwa Number.4 in 2003 says the drinks containing ethanol $\left(\mathrm{C}_{2} \mathrm{H}_{5} \mathrm{OH}\right)$ more than one persen are categorized haram. Because of that, need some research to see the impact of duration fermentation to alcohol concentration on black sticky tapai in Batusangkar city. The reaserch data was obtained by distillation from various duration of fermentation. The result data were analyzed by product moment correlation test $(\alpha=5 \%)$. Base on the research conducted, obtained information that in black sticky tapai contain etanol which has increased alcohol concentration along with the increase of fermentation duration. However, it becomes contradictory with the result of analysis where $\mathrm{Y}=$ $3,635-15,54 \mathrm{X}, \mathrm{t}$ arithmetic $\leq \mathrm{t}$ table, that is $0,16 \leq 3,18$. This conclusions that there is no relationship between duration of fermentation with alcohol concentration.
\end{abstract}

Keywords: Tapai Ketan, Fermentation, Alcohol.

\section{PENDAHULUAN}

Tapai merupakan salah satu jenis makanan hasil proses fermetasi. Ada beberapa jenis tapai, seperti tapai ubi dan ketan hitam. Tapai adalah ketan hitam yang dibuat dengan memfermentasikan ketan hitam dengan ragi. Ragi atau khamir mempunyai kemampuan untuk memecah pangan karbohidrat menjadi alkohol dan karbondioksida. Reaksi yang terjadi dalam fermentasi alkohol sebagai berikut:

$$
\mathrm{C}_{6} \mathrm{H}_{12} \mathrm{O}_{6} \rightarrow 2 \mathrm{C}_{2} \mathrm{H}_{5} \mathrm{OH}+2 \mathrm{CO}_{2} \ldots \text { (1) }
$$$$
\text { Karbohidra etano karbondioksida }
$$

Berdasarkan uraian dan reaksi kimia pada persamaan 1 dapat disimpulkan bahwa proses fermentasi ketan hitam dengan ragi dapat menghasilkan alkohol/ Etanol. Penentuan kadar alkohol di dalam tape ketan sudah lama dilakukan (Cronk, Mattick, Steinkraus, \& Hackler, 1979) sudah melakukan penelitian tentang kadar alkohol yang dihasilkan oleh fermentasi tape ketan. T.C Cronk membuktikan bahwa dihasilkan iso butanol, active amyl dan iso amil yang dihasilkan selama proses fermentasi tape ketan. Fakta yang cukup mengejutkan adalah lamanya proses fermentasi ternyata dapat meningkatkan kadar alkohol di dalam tape, seperti dikutip dari penelitian (Mulja, 2003). Mulja menemukan bahwa terjadi kenaikan alkohol di dalam nira siwalan sebesar 4,48\%. Kenyataannya, Fatwa MUI No. 11 Tahun 2009 tentang Alkohol menerangkan 
Sari, M., Fajar, N. 2018. Analisa Kualitatif dan Kuantitatif Kandungan Alkohol pada Tapai Ketan di Kota Batusangkar. Sainstek : Jurnal Sains dan Teknologi. 10 (2) : 33-36

bahwa minuman beralkohol adalah minuman yang mengandung etanol, dan senyawa turunan lainnya seperti metanol, asetaldehida dan etil asetat yang dibuat secara fermentasi dengan rekayasa dari berbagai jenis bahan baku nabati yang mengandung karbohidrat ketentuan hukumnya adalah Haram. Oleh karena itu dirasa perlu untuk melakukan analisa terhadap kandungan etanol pada "tapai" ketan di kota Batusangkar. Adapun analisa terhadap kandungan etanol dilakukan dengan analisa kualitatif dan kuantitatif. Analisa kualitatif diuji dengan pereaksi iodoform dan potasium dikromat sedangkan analisa kuantitatif dilakukan dengan metode titrasi alkalimetri dan spektrofotometri.

\section{METODE PENELITIAN}

\section{Pembuatan Tapai Ketan}

Sampel beras ketan hitam diambil secara acak dari pasar yang ada di Kota Batusangkar. Tidak ada perlakuan khusus terhadap sampel beras ketan sebelum difermentasi menjadi tapai. Sampel beras ketan dibersihkan kemudian ditimbang sebanyak 500 gram, selanjutnya dimasak dengan cara dikukus menggunakan dandang dengan air sebanyak $300 \mathrm{ml}$. Setelah masak kemudian didinginkan diatas nampan. kemudian diberi sedikit larutan gula sebagai starter, selanjutnya diberi serbuk ragi atau yeast sebagai fermentatornya sebanyak 25 gram dan diaduk sampai rata. Langkah selanjutnya dimasukkan kedalam daun pisang, dibiarkan terjadi fermentasi. Lama nya waktu fermentasi divariasikan menjadi; 1, 2, 3, 4 dan 5 hari.

2. Destilasi Alkohol Pada Tape singkong

Ditimbang 25 gram tape ketan hitam dan ditumbuk sampai halus. Ditambah $25 \mathrm{~mL}$ aquades. Campuran dimasukkan dalam labu alas bulat dan labu destilat dipasang pada alat destilasi dan ditetapkan pada suhu $78{ }^{\circ} \mathrm{C}-100$ ${ }^{\circ} \mathrm{C}$. Didestilasi dan destilat hasil destilasi ditampung dalam tempat terpisah. Destilasi dihentikan jika sudah tidak ada destilat yang menetes dalam penampung. Destilat yang didapat ditimbang dalam satuan gram, lalu dimasukkan dalam botol kecil dengan ukuran $10 \mathrm{ml}$ dan ditutup rapat.

3. Variabel Penelitian

Variabel bebas pada penelitian ini adalah sampel tapai ketan yang didestilasi agar diperoleh alkohol sedangkan variabel terikat adalah kadar etanol yang dihasilkan.

4. Analisa Senyawa Etanol di dalam Destilat

Analisa kualitatif dapat dilakukan dengan cara: a)Reaksi warna menggunakan Potasium Dikromat $3,5 \%$; b) uji dengan iodoform; sedangkan analisa kuantitatif dilakukan dengan a)metode titrasi alkalimetri; b)Uji spektrofotometer

5. Variabel Penelitian

Variabel bebas pada penelitian ini adalah sampel tapai ketan yang didistilasi agar diperoleh alkohol sedangkan variabel terikat adalah kadar etanol yang dihasilkan.

Teknik Analisi Data

Data yang telah diperoleh dalam hasil penelitian ini dianalisis dengan analisis varians (ANOVA) untuk menguji adanya perbedaan konsentrasi kadar (\%) etanol tape singkong selama fermentasi. Apabila terjadi perbedaan yang signifikan maka dilanjutkan dengan uji BNT dengan taraf $0,5 \%$.

\section{HASIL DAN PEMBAHASAN}

Dari uji reaksi menggunakan potasium dikromat menunjukkan perubahan warna menjadi warna jingga (Muchtaridi, Musfiroh, Hambali, \& Indrayati, 2012). Adapun mekanisme reaksi identifikasi alkohol dengan pereaksi potasium dikromat dapat dilihat sebagai berikut (Vogel, 1958):

$$
\begin{aligned}
& 3 \mathrm{R}-\mathrm{CH}_{2} \mathrm{OH}+\mathrm{K}_{2} \mathrm{Cr}_{2} \mathrm{O}_{7}+4 \mathrm{H}_{2} \mathrm{SO}_{4} \rightarrow 3 \mathrm{R}- \\
& \mathrm{C}-\mathrm{H}=\mathrm{O}+\mathrm{Cr}_{2}\left(\mathrm{SO}_{4}\right)_{3}+\mathrm{K}_{2} \mathrm{SO}_{4}+7 \mathrm{H}_{2} \mathrm{O} \ldots \text { (2) }
\end{aligned}
$$


Sari, M., Fajar, N. 2018. Analisa Kualitatif dan Kuantitatif Kandungan Alkohol pada Tapai Ketan di Kota Batusangkar. Sainstek : Jurnal Sains dan Teknologi. 10 (2) : 33-36

Tabel 1. Hasil Pengujian Kadar Alkohol dengan Titrasi Alkalimetri

\begin{tabular}{ccc}
\hline No & Fermentasi hari ke- & $\%$ Kadar alkohol \\
\hline 1 & Pertama & 0,00041 \\
2 & Kedua & 0,00024 \\
3 & Ketiga & 0,00018 \\
4 & keempat & 0,0015 \\
\hline
\end{tabular}

Uji reaksi dengan iodoform juga menunjukkan hasil yang sama dengan uji reaksi sebelumnya yang ditandai dengan terbentuknya endapan kuning pada larutan (Muchtaridi et al., 2012). Adapun mekanisme reaksinya dapat dilihat sebagai berikut (Vogel, 1958) :

$\mathrm{C}_{3} \mathrm{H}_{7} \mathrm{OH}+\mathrm{NaOH}+\mathrm{I}_{2} \rightarrow$ Endapan kuning.. (3)

Dengan demikian dapat disimpulkan bahwa di dalam "tapai" ketan di Kota Batusangkar mengandung alkohol. Hal ini sesuai dengan mekanisme reaksi fermentasi (Berlian, Aini, \& Ulandari, 2016);

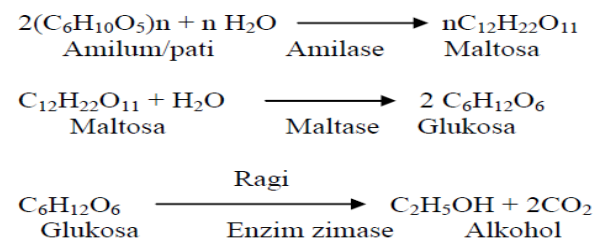

Hasil pengujian kadar alkohol dengan menggunakan metode titrasi alkalimetri dapat dilihat pada Tabel 1.

Pengujian dengan metode titrasi alkalimetri ini dilakukan terhadap hasil fermentasi yang ditentukan sebagai asam oksalat dengan menggunakan larutan standar
$\mathrm{NaOH} \mathrm{0,1} \mathrm{M} \mathrm{yang} \mathrm{sudah} \mathrm{distandarisasi} \mathrm{terlebih}$ dahulu dengan asam oksalat (Sutanto \& Hp, 2006). Pengujian dengan metode titrasi alkalimetri ini dilakukan degan variasi lama fermentasi. Untuk pembuktian hukum Lambert Beer dibuat dari larutan etanol dengan variasi konsentrasi $1 \%, 3 \%, 5 \%$ dan $7 \%$ dan dibaca serapannya pada panjang gelombang $600 \mathrm{~nm}$. Dari hasil penelitian terlihat peningkatan kandungan alkohol seiring dengan lamanya fermentasi. Hasil yang sama juga dapat dilihat pada pengujian dengan metoda spektrofotometer pada Tabel 2 .

Hubungan antara serapan dengan kadar alkohol diperoleh persamaan Lambert Beer yaitu $\mathrm{Y}=3,635-15,54 \mathrm{X}$ dengan nilai $\mathrm{r}$ sebesar 0,16 . Berdasarkan penelitian yang sudah dilakukan diperoleh informasi bahwa di dalam tapai ketan yang berasal dari Tanah Datar ternyata mengandung etanol yang mengalami peningkatan kadar seiring dengan bertambah-nya masa fermentasi. Hal yang sama juga pernah dialami oleh peneliti sebelumnya. Hasanah dkk, mengalami peningkatan alkohol sebesar 2\% pada hari ke-2. Pada penelitiannya Muchtariadi mengalami peningkatan alkohol dengan kadar yang sama pada hari ke-5.

Tabel 2. Hasil Uji Kandungan Alkohol dengan Metoda Spektrofotometer

\begin{tabular}{cccc}
\hline No & Fermentasi Hari & Konsentrasi & Absorbansi (serapan) \\
\hline 1 & Pertama & $1 \%$ & 0,005 \\
2 & Kedua & $3 \%$ & 0,008 \\
3 & Ketiga & $5 \%$ & 0,05 \\
4 & Keempat & $7 \%$ & 0,13 \\
\hline
\end{tabular}


Sari, M., Fajar, N. 2018. Analisa Kualitatif dan Kuantitatif Kandungan Alkohol pada Tapai Ketan di Kota Batusangkar. Sainstek : Jurnal Sains dan Teknologi. 10 (2) : 33-36

Perbedaaan kenaikan kadar alkohol kemungkinan disebabkan oleh perbedaan jenis bahan baku pembuatan tapai ketan. Beras ketan sebagai bahan baku utama pembuatan ketan memiliki varietas yang berbeda-beda sehingga kandungan amilosa dan amilopektinnya juga berbeda. Beras ketan yang digunakan dalam penelitian ini kemungkinan mengandung sekitar 20\% kadar amilopektin, terlihat dari struktur morfologi beras ketan yang lengket ketika sudah dimasak. Kadar ini tidak dapat dipastikan karena tidak dilakukan analisa terhadap kandungan amilopektik beras ketan yang digunakan dalam penelitian. Data yang telah di peroleh dalam hasil penelitian ini dianalisis dengan uji korelasi product moment ( $\alpha=5 \%$ ). Berdasarkan penelitian yang sudah dilakukan diperoleh informasi bahwa di dalam tapai ketan yang berasal dari Tanah Datar ternyata mengandung etanol yang mengalami peningkatan konsentrasi alkohol seiring dengan bertambahnya lama waktu fermentasi. Akan tetapi menjadi kontradiktif dengan hasil analiis data dimana $\mathrm{Y}=3,635-15,54 \mathrm{X}, \mathrm{t}$ hitung $\leq \mathrm{t}_{\text {tabel }}$, yaitu $0,16 \leq 3,18$. Hal ini menerangkan bahwa tidak ada hubungan antara pengaruh lama waktu fermentasi dengan konsentrasi alkohol. Hasil penelitian ini diduga dipengaruhi oleh beberapa faktor seperti kestabilan alat pengukuran spektrofotometri serta proses fermentasi yang tidak berjalan sempurna. Adapun kestabilan alat spektrofotometer mengakibatkan data yang terbaca menjadi tidak valid, sedangkan proses fermentasi yang tidak berjalan sempurna mengakibatkan kadar air di dalam tapai ketan menjadi banyak sehingga ketika dilakukan pengukuran kuantitatif kemungkinan komposisi air ikut terukur.

\section{KESIMPULAN}

Adapun kesimpulan dari penelitian ini adalah bahwa telah dilakukan analisa kualitatif dan kuantitatif kandungan alkohol pada tapai ketan dikota Batusangkar. Meskipun dalam uji statistik nya menunjukkan tidak terdapat korelasi antara kandungan alkohol dengan lama nya waktu fermentasi akan tetapi data-data yang diperoleh memperlihatkan kenaikan kadar alkohol dengan lamanya masa fermentasi.

Saran untuk penelitian ini adalah agar memperhatikan kestabilan alat pengukuran sebelum dilakukan penelitian.

\section{DAFTAR KEPUSTAKAAN}

Berlian, Z., Aini, F., \& Ulandari, R. (2016). Uji Kadar Alkohol pada Tapai Ketan Putih dan Singkong Melalui Fermentasi dengan Dosis Ragi yang Berbeda. Jurnal Biota, 2(1), 106-111.

Cronk, T. C., Mattick, L. R., Steinkraus, K. H., \& Hackler, L. R. (1979). Production of Higher Alcohols During Indonesian Tape Ketan Fermentation. Applied and Environmental Microbiology, 37(5), 892896. Retrieved from http://aem.asm.org/

Muchtaridi, Musfiroh, I., Hambali, N. N., \& Indrayati, W. (2012). Determiation of Alcohol Contents of Fermentated Black Tape Ketan Based on Different Fermentation Time Using Spesific Gravity, Refractive Index and GC- MS Methods. Journal of Microbiology, Biotechnology and Food Science, 2(3), 933-946.

Mulja, M. (2003). Pengembangan Metode Kromatografi Gas Untuk Penetapan Kadar Etanol dalam Nira Siwalan (Borassus flabellifer Linn.). Media Majalah Farmasi Airlangga (Airlangga Journal of Pharmacy), 3(1).

Sutanto, T. D., \& Hp, A. M. (2006). Studi Kandungan Etanol Dalam Tapai Hasil Fermentasi Beras Ketan Hitam Dan Putih. Jurnal Gradien, 2(1), 123-125.

Vogel, A. (1958). Quntitative Inorganic Analysis Theory and Practice. London: Longmans Green and Co. 